\title{
A neglected predictor of environmental damage: The ecological paw print and carbon emissions of food consumption by companion dogs and cats in China
}

Citation for published version (APA):

Su, B., Martens, P., \& Enders-Slegers, M-J. (2018). A neglected predictor of environmental damage: The ecological paw print and carbon emissions of food consumption by companion dogs and cats in China. Journal of Cleaner Production, 194, 1-11. https://doi.org/10.1016/j.jclepro.2018.05.113

Document status and date:

Published: 01/09/2018

DOI:

10.1016/j.jclepro.2018.05.113

Document Version:

Publisher's PDF, also known as Version of record

Document license:

Taverne

Please check the document version of this publication:

- A submitted manuscript is the version of the article upon submission and before peer-review. There can be important differences between the submitted version and the official published version of record.

People interested in the research are advised to contact the author for the final version of the publication, or visit the DOI to the publisher's website.

- The final author version and the galley proof are versions of the publication after peer review.

- The final published version features the final layout of the paper including the volume, issue and page numbers.

Link to publication

\footnotetext{
General rights rights.

- You may freely distribute the URL identifying the publication in the public portal. please follow below link for the End User Agreement:

www.umlib.nl/taverne-license

Take down policy

If you believe that this document breaches copyright please contact us at:

repository@maastrichtuniversity.nl

providing details and we will investigate your claim.
}

Copyright and moral rights for the publications made accessible in the public portal are retained by the authors and/or other copyright owners and it is a condition of accessing publications that users recognise and abide by the legal requirements associated with these

- Users may download and print one copy of any publication from the public portal for the purpose of private study or research.

- You may not further distribute the material or use it for any profit-making activity or commercial gain

If the publication is distributed under the terms of Article $25 \mathrm{fa}$ of the Dutch Copyright Act, indicated by the "Taverne" license above, 


\title{
A neglected predictor of environmental damage: The ecological paw print and carbon emissions of food consumption by companion dogs and cats in China
}

\author{
Bingtao Su ${ }^{\text {a, }}$, Pim Martens ${ }^{a}$, Marie-José Enders-Slegers ${ }^{b}$ \\ a International Centre for Integrated Assessment and Sustainable Development (ICIS), Maastricht University, P.O. Box 616, 6200 MD Maastricht, The \\ Netherlands \\ ${ }^{\mathrm{b}}$ Faculty of Psychology and Educational Sciences, Open University, P.O. Box 2960, 6401 DL Heerlen, The Netherlands
}

\section{A R T I C L E I N F O}

\section{Article history:}

Received 9 November 2017

Received in revised form

9 April 2018

Accepted 15 May 2018

Available online 15 May 2018

\section{Keywords:}

Ecological paw print

Carbon emission

Energy consumption

Dogs

Cats

China

\begin{abstract}
A B S T R A C T
Food consumption has considerable impacts on the environment. Recently, increasing numbers of companion animal owners feed their animals with high nutritional food, which requires much land space and has great impacts on carbon emissions. Therefore, the environmental impacts of food consumption by companion animals can be significant, especially in a country with a large companion animal population, like China. In the present study, the ecological indicators of the ecological paw print (EPP), carbon emission and energy consumption have been introduced for the first time to quantify the environmental impacts of food consumption by companion dogs and cats in China. Our results showed that the dietary EPP and carbon emissions of an average-sized dog relying on commercial dry food ( 0.82 -4.20 ha year $^{-1}$ and $0.037-0.190$ ton. year ${ }^{-1}$ ) were ca. eight and three times higher than those of the dog relying on human leftover food $\left(0.11-0.53\right.$ ha year $^{-1}$ and $0.014-0.064$ ton. year $\left.^{-1}\right)$. There were more than 27.4 million companion dogs and 58.1 million companion cats in China in 2015. Assuming all these dogs and cats eat commercial dry food, the dietary EPP of the total dogs and cats was 43.6-151.9 million ha. year $^{-1}$, which was equivalent to the dietary ecological footprint (EF) of $5.1 \%-17.8 \%$ (70.3-245.0 million) of Chinese people in 2015. The annual food consumption of all these dogs and cats was responsible for up to 2.4-7.5 million tons carbon emissions, which was equivalent to the entire carbon emissions of $2.5 \%$ $-7.8 \%$ (34.3-107.1 million) of Chinese people in terms of food consumption in 2015. Our results also demonstrated that some companion animals (especially large dogs) consumed more food energy than their actual needs to keep normal activity, which resulted in food waste and exacerbated the environmental burden. This research develops an accurate method for companion animals' dietary EPP calculation and quantifies the significant environmental impacts by investigating their dietary carbon emissions and energy consumptions. Findings from this study will motivate companion animal owners to reconsider the feeding regimens and husbandry activities, improve owners and even the whole Chinese people's awareness of sustainability, and ultimately promote the whole country's sustainable development.
\end{abstract}

() 2018 Elsevier Ltd. All rights reserved.

\section{Introduction}

Companion animals are an integral part of human society in the world. They provide a host of therapeutic, physiological and psychological benefits to people (Okin, 2017; Su et al., 2018), such as reducing risk of heart attacks, improving survival rates, increasing physical activity and providing emotional and social support

\footnotetext{
* Corresponding author.

E-mail address: Bingtao.Su@maastrichtuniversity.nl (B. Su).
}

(Friedmann and Thomas, 1995; Qureshi et al., 2009; Wood et al., 2015). According to the data from the Vetnosis and The European Pet Food Industry Federation (FEDIAF), there were 223 million registered companion dogs and 220 million registered companion cats in the world in 2014. These animals require food and space, which might be suitable as human food and arable land to produce human food. Previous research has demonstrated that the land use for only dried cat food in the top ten cat-owning countries in the world is equal to an area about six times the size of New Zealand or Japan (Vale and Vale, 2009). This number dramatically increases if 
we include companion dogs' food consumption. Therefore, the food consumption by companion animals is of importance to the increasing level of environmental degradation and needs further investigations.

In the present study, we questioned the environmental impacts of food consumption by companion dogs and cats. We selected China as the representative due to its large population of companion animals. Further, an examination of the data from the China industry information network showed that the estimated companion dog population in China was 27.4 million and the cat population was 58.1 million in 2015 . These numbers were expected to increase by $10 \%$ annually, because China has entered into an aging society and people, in particular old people like empty-nesters, are increasingly likely to own one or more companion animals (MIIT, 2015; Wu et al., 2015). Given the rapid growth of the economy, urbanization and industrialization, China's environmental problems and the ecological deficit have increased dramatically in the last decade and the increasing number of companion animals' impacts on carbon emissions would be more serious than we heretofore imagined (Gao and Tian, 2016; Wang et al., 2016). Additionally, due to the improving living standards and the increasing purchase power, most companion animal owners have started to pay much attention to their animals' nutritional requirements. Companion dog and cat's main dietary source, leftovers from human food, has begun to be replaced by the betterquality commercial pet food, which includes more animal products and contributes to more environmental impacts (Carrión and Thompson, 2014). These trends may aggravate the environmental impacts of food consumptions by companion animals and can increase the environmental burden of not only China but also the whole world. However, case studies evaluating the magnitude of these environmental impacts are rare and the development of related policies in addressing these potential impacts deserves more attention.

The ecological indicators of the dietary "Ecological Paw Print" (EPP), carbon emission and energy consumption were introduced to investigate the magnitude of the environmental impacts of companion animals. The EPP was originated from the "Ecological Footprint" (EF). The EF was first introduced by Wackernagel and Rees (1998) as a measure of sustainability. It relates to how much productive land is needed for an individual or population to maintain itself and to process the manufactured waste beside given technological development (Fiala, 2008; Szigeti et al., 2013). In New Scientist, David Mackay, a physicist at the University of Cambridge estimated the EPP of a cat to represent about $2 \%$ of the average British person's EF (Ravilious, 2009). More shockingly, when comparing data from a study conducted by Vale and Vale (2009), it appears the dietary EPP of some large dog breeds is as high as the EF for individuals in some undeveloped countries in the world (Schwartz, 2014). In the US, dogs and cats consume about $19 \% \pm 2 \%$ of the amount of dietary energy that humans do, and through their diet, constitute about $25-30 \%$ of the environmental impacts from animal production in terms of the use of land, water, fossil fuel, phosphate, and biocides (Okin, 2017). These studies imply that the negative environmental impacts of food production and consumption by companion animals are significant and expected to grow worldwide in the near future (Reijnders and Soret, 2003).

The primary purpose of this research was to investigate the environmental impacts of food consumption by companion dogs and cats in China. Specifically, we first quantified companion animals' food consumption, dietary EPP and carbon emissions regarding human leftover food and commercial dry food. Given companion animals' strong impacts on the environment, reducing their food consumption is potentially the most direct attempt to reduce their dietary EPP and carbon emissions. In order to determine feeding directions and simultaneously guarantee companion animals' health, we additionally compared their energy requirement and energy consumption regarding both diet types. To the best of our knowledge, this is the first study to approximate and highlight the dietary EPP and carbon emissions of companion dogs and cats by utilizing market-wide knowledge of pet food and direct data on pet food consumptions. Therefore, our results will be representative of the actual relationship between companion animals' food consumption and their environmental impacts in China, and will be more powerful and valuable compared to the results that based on stochastic data in previous studies. The accurate and accessible methods and frameworks in this research can serve as a motivational platform for other environmental studies related to the food consumption by other animal types and us humans. Findings and recommendations in this study will motivate companion animal owners to reconsider the feeding regimens and husbandry activities, encourage the government and policymakers to reconstruct their policies concerning companion animals (e.g., taxation and registration), and ultimately promote Chinese people's awareness of sustainability and the whole country's sustainable development.

\section{Methods}

\subsection{The schematic overview of the methods}

A schematic overview of the methods that we proposed in the present research is presented in Fig. 1. This schematic overview described how we quantified the environmental indicators of the dietary EPP, carbon emission and energy consumption in this research.

\subsection{Application of the ecological footprint (ecological paw print) analysis}

The EF represents demand for ecosystem products and services in terms of land use types (Geng et al., 2014; Wackernagel and Rees, 1998). The ecological footprint analysis (EFA) has been used widely for fundamental studies of sustainable development (Lambrechts and Van Liedekerke, 2014; Liu et al., 2017). EFA categorizes bioproductive land into six land use types: arable land, grazing land, forest land, fishing grounds, built-up land and energy land (Geng et al., 2014; Wackernagel and Rees, 1998).

Generally, in national or global EF accounts, the EF calculation is usually estimated by adding the imports and subtracting the exports to the output in the study system (Fu et al., 2015; Wackernagel and Rees, 1998). However, at scales smaller than the world as a whole, the EF calculation assesses the resources related to the final consumption activities of that population (Geng et al., 2014; Kitzes et al., 2008). Considering that our study mainly focused on companion dogs and cats' dietary EPP, the calculation is carried out directly through the final consumption data rather than the production and trade data.

The dietary EPP calculation is based on the per capita dog/cat consumption of food resources in various categories. The food consumption items include poultry (chicken) and cereal regarding commercial dry food while including beef, mutton, port, poultry, fish, oil, egg, milk, grain, vegetable and fruit regarding leftovers from human food (according to the categories of human food in the China Statistical Yearbook). The land types of arable land, grazing land, and fishing grounds were included in the present study. Additionally, considering the resource consumption in the processes of food production (including leftover food cooking) and transportation (based on the resource consumption by train sets because rail freight is the most popular way for pet food 


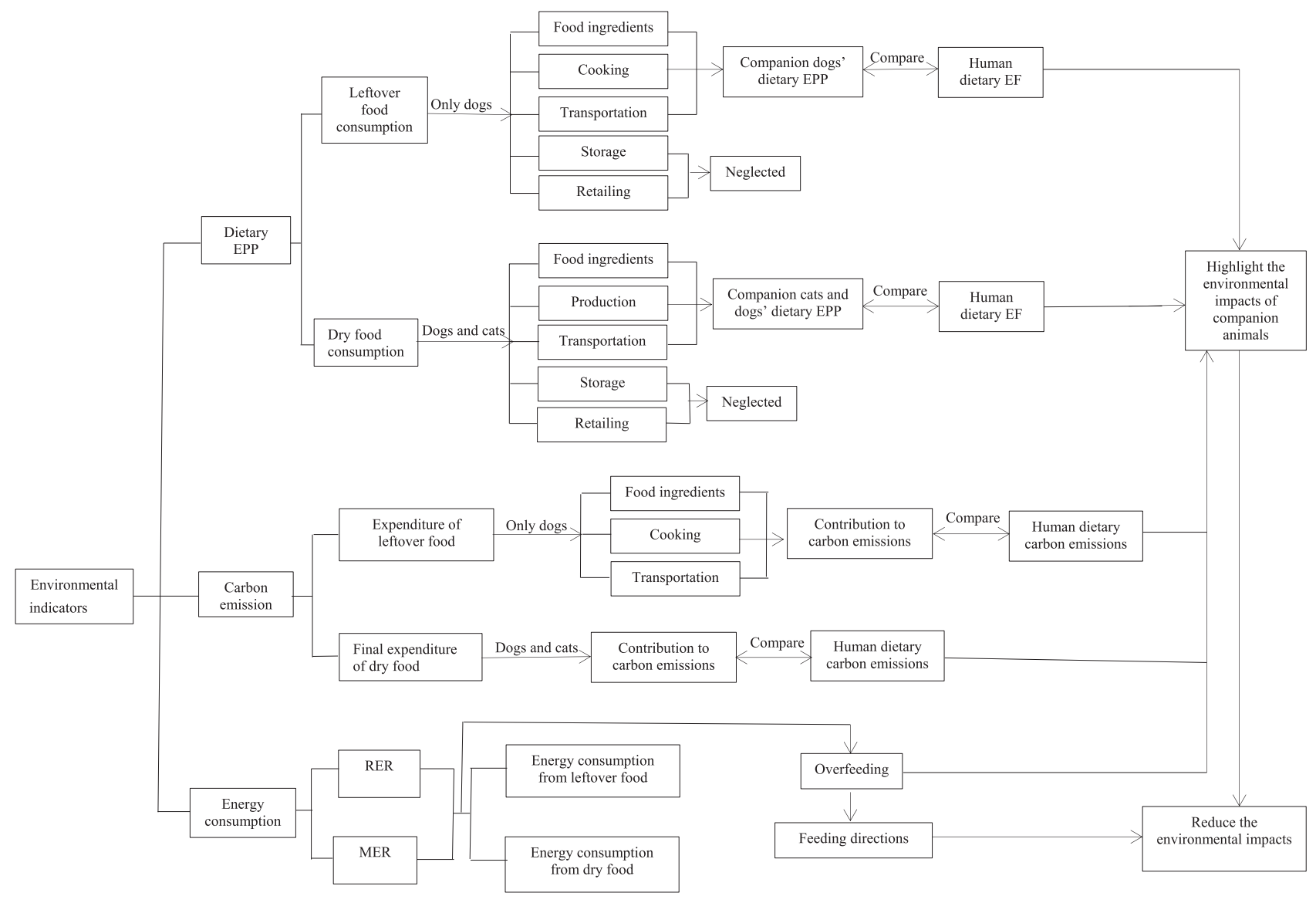

Fig. 1. The schematic overview of the methods.

transportation in China) (Canning, 2011; Mukherjee, 2008; Wakeland et al., 2012), the energy land was also involved in the calculation of the dietary EPP. Although the pet food business has increased rapidly in China, it is still not as popular as that in the developed countries and many pet foods are sold through online retailers. Therefore, the EPP from retailing process would be very small and can be neglected. Due to the short periodicity of the food production and the limited requirements for temperature and humidity during storage, the proportion of the storage EPP is also very small and can be reasonably neglected.

The calculations of the dietary EPP are as shown below:

First, the per capita dietary EPP component of each consumption item should be calculated by the equation below (Du et al., 2006):

$A_{i}=C_{i} / Y_{i}$

Where,

$i=1,2 \ldots$, is the number of consumption items; $A_{i}=$ per capita dietary EPP component of item $i$ (ha); $C_{i}=$ per capita consumption of item $i(\mathrm{~kg}$ or $\mathrm{t}) ; Y_{i}=$ the annual average productivity in the world of item $i(\mathrm{~kg} / \mathrm{ha}$ or $\mathrm{t} / \mathrm{ha})$.

Then, the equation of per capita dietary EPP is as shown below (Du et al., 2006; Liu et al., 2017):

$$
E P P_{\text {dietary }}=\sum_{i=1}^{n} r_{i} A_{i}
$$

Where, $r_{i}$ is the equivalence factor.

To align the measurement units, all four land types should be converted using the equivalence factors. The equivalence factor is the ratio of the average productive capacity of an area and the world (Liu et al., 2017; Toth and Szigeti, 2016; Wackernagel et al., 1999).

The dietary EPP of companion dogs was calculated based on their consumption of leftover food and commercial dry food (chicken-based), which are the two most common pet food types in China. Considering that companion cats are carnivores and not adapted to human food, the dietary EPP of companion cats was calculated only based on their consumption of commercial dry food (chicken-based). Notably, as for the calculation of dietary EPP regarding commercial dry food, we assumed both the crude protein and fat were from chicken, and the carbohydrate was from cereals. We used the raw chicken and cereal in the calculation process, and the equations of the per capita consumption of raw chicken and cereal are as shown below:

Chicken $_{\text {raw }}(\mathrm{kg})=\frac{\left(\text { protein }_{\text {commercial food }}+\text { fat }_{\text {commercial food }}\right) \% \times \text { food consumption }(\mathrm{kg})}{\left(\text { protein }_{\text {raw chicken }}+\text { fat }_{\text {raw chicken }}\right) \%}$ 
Cereal $_{\text {raw }}(\mathrm{kg})=\frac{\text { carbonhydrate }_{\text {commercial food } \% \times \text { food consumption }(\mathrm{kg})}}{\text { carbohydrate }_{\text {raw }} \text { cereal } \%}$

According to the data from USDA (United States Department of Agriculture), Food Composition Databases, the average percentages of protein and fat in raw whole chicken are $17.33 \%$ and $17.98 \%$, respectively, while the average percentage of carbohydrate in raw cereal is $73.3 \%$. The proprietary nature and incredible variety of pet food recipes make an exact calculation impossible (Okin, 2017). Hence, calculations in this part were made on the assumptions that 1) the weight of protein and fat in raw chicken and carbohydrate in raw cereal did not change during the process of industrial production (the conversion rate is one to one) and 2) these two raw ingredients make up nearly all of the mass of the pet food.

\subsection{The carbon emissions}

According to the Consumer Lifestyle Approach (CLA), household carbon emissions are related to individual (household) consumption behaviors (Bin and Dowlatabadi, 2005; Xu et al., 2016). Carbon emissions contain both direct (e.g., electricity, natural gas, domestic cars) and indirect carbon emissions (e.g., clothing, eating, residing). Companion animals as "stuff we have at home" also contribute to the household carbon emissions. Considering that companion animals' direct and some indirect carbon emissions (e.g., residing) are difficult to separate out from household carbon emissions, in the present study, we only measured their indirect carbon emissions from food consumption.

The per capita carbon emission was calculated as follows (Wei et al., 2007; Xu et al., 2016):

$\mathrm{CO}_{2}=\mathrm{CI}_{f} \times X$

Where,

$\mathrm{CI}_{f}$ refers to the carbon emission intensity of food consumption in China (food $0.23 \mathrm{t} / 10^{4} \mathrm{CNY}$, transportation $0.07 \mathrm{t} / 10^{4} \mathrm{CNY}$, cooking $0.08 \mathrm{t} / 10^{4} \mathrm{CNY}$ ) (Wei et al., 2007; Xu et al., 2016), and $\mathrm{X}$ refers to the final expenditure of food consumption for companion animals (CNY).

Notable, the expenditure of commercial dry food was calculated according to the final price, which includes the cost of all the ingredients and processes (e.g., fresh food, food production, and transportation). The price of food items in human leftover food was calculated according to the fresh food, but the expenditure of food transportation and cooking was also included when we calculated the carbon emissions of human leftover food (Wei et al., 2007; Xu et al., 2016).

\subsection{The energy requirement}

The "Resting Energy Requirement" (RER) is the amount of calories required by an animal at rest in a thermoneutral environment and does not support any exercise, growth, or reproduction. It is a function of metabolic body weight and can be calculated using the formula (Fleeman and Owens, 2007):

$R E R($ Kcal/day $)=70 \times\left(B W t_{\text {kg }}\right)^{0.75}$

The "Maintenance energy requirement" (MER) is defined as the energy required to keeping an animal in a "maintenance state", or maintaining a normal activity (Fleeman and Owens, 2007; Flynn et al., 1996; Jones and Ackerman, 2016; Streeter and Wakshlag, 2015).

The following is a guide to the calculation of MER for companion dogs and cats.

For companion dogs (Fleeman and Owens, 2007; Linder and Freeman, 2010; Thatcher et al., 2010):

$$
M E R_{d o g}=X(1.39) \times R E R
$$

For companion cats (Linder and Freeman, 2010; Thatcher et al., 2010):

$M E R_{\text {cat }}=X(1.27) \times R E R$

$\mathrm{X}$ refers to a coefficient. The coefficients (1.39 for companion dogs and 1.27 for companion cats) were calculated according to the results from Linder and Freeman (2010).

\subsection{The metabolizable energy in feeding stuff}

The metabolizable energy in leftovers from human food $\left(M E_{l}\right)$ is calculated by the formula below:

$M E_{l}=\sum_{i=1}^{n} C_{i} \times Y_{i}(i=1,2,3,4,5,6,7,8,9)$

Where, i refers to consumption items, $\mathrm{C}$ means the weight of food consumption, Y refers to the calorie content per weight $(\mathrm{kg})$ of consumption item in human food.

The calorie content of human leftover food was calculated according to the information from the Calorie Control Council. We chose ten most conventional cooking ways for each consumption item in human food (with the exception of milk and oil) and calculated the average calorie content of each item.

The calorie content of commercial dry food is dependent on the amounts of crude protein, crude fat, and carbohydrate in the product. According to the information from the Association of American Feed Control Officials (AAFCO), carbohydrates are estimated by calculating the "nitrogen-free extract" (NFE) in the product. This is determined by subtracting the average of each of the other components (percent crude protein, crude fat, crude fiber, moisture, and ash) from 100 . The equation of the calculation is as shown below:

$$
\begin{aligned}
\text { NFE }= & 100-(\text { crude protein }+ \text { crude fat }+ \text { crude fiber } \\
& + \text { moisture }+ \text { ash })
\end{aligned}
$$

The metabolizable energy of commercial food $\left(\mathrm{ME}_{\mathrm{c}}\right)$ is calculated by the following formula (Meldrum et al., 2017):

$$
M E_{c}=[(3.5 \times \text { crude protein })+(8.5 \times \text { crudefat })+(3.5 \times N F E)] \times 10
$$

\subsection{Data}

In order to complete our analysis on Chinese companion animals' dietary EPP, carbon emissions, and energy consumption, several approaches for data collection were introduced. 
An online survey was carried out amongst a group of Chinese companion dog and/or cat owners from 557 people among a sampling frame of 3006 people throughout the mainland of China. In order to keep the answer consistent, respondents were asked to respond for only one dog or cat. For those owners who owned more than one companion animal, we asked them to respond according to the animal they had owned the longest. In the questionnaire, respondents were asked to supply information about their companion animals' basic characteristics (species, breed, gender, size, age, neutered status and owners' perceptions of their animals' health condition), as well as their husbandry practices (How often do you visit the vet with your companion animals?; how often and how long do you go for a walk with your dog?; How often does your cat go outside?; How often and how much do you feed your dog or cat?; How often do you brush your dog [change your cat's litter]?; Does your cat sit frequently on your lap?; Is your dog friendly to strangers?; Can your dog/cat stay alone at home?; Where does your dog/cat sleep?; Who is taking care of your dog/cat when you are not around?). Additionally, respondents were asked if they were the main caregivers of their pets, whether they have other pets and how many years they have owned their pets.

Additionally, we reviewed the secondary sources of information from the China Statistical Yearbook, China Industry Information Yearbook, China industry information network, government reports, statistical reports, published papers, international organizations and web pages. Data on the composition items, the price and calorie content of each item in human food were derived from the China Statistical Yearbook, 2015 and the Calorie Control Council. Data were reported as the mean score (Table 1 ). Data on the resource consumption of food production (including leftover food cooking) and transportation was calculated according to the information from the China Statistical Yearbook and the National Bureau of Statistics of China. The nutritional components, the metabolizable energy and the price of the commercial dry food were calculated according to the data from the seven most famous Chinese pet food brands (RoyalCanin, Purina, Pedigree, ProPlan, Bridge, Care and Myfoodie), which was evaluated by Chinese Brand Research Institute regarding brand popularity, product sales, employee numbers, asset size and operating conditions. Data were shown in Table 2.

Data on global production, land use for average productivity and equivalence factors were taken from the United Nations Food and Agriculture Organization (FAO), the National Bureau of Statistics and published papers (Table 3) (Liu et al., 2017; Shi et al., 2015; Wackernagel et al., 1999; Wackernagel and Rees, 1998). These factors were used to calculate the dietary EPP components of grazing land, arable land, fishing grounds and energy land.

Table 1

The percentage, price and calorie content of each composition item in the human food.

\begin{tabular}{llll}
\hline Items & Percent $(\%)$ & Price $($ Yuan $/ \mathrm{kg})$ & $\mathrm{Kg} / \mathrm{Kcal}$ \\
\hline Beef and mutton & 1.07 & 65.64 & 1913 \\
Pork and other meat & 6.85 & 24.84 & 2943 \\
Poultry & 2.57 & 20.04 & 2432 \\
Fish & 4.03 & 15.33 & 873 \\
Oil & 3.04 & 10.10 & 8840 \\
Egg & 2.88 & 9.83 & 906 \\
Milk & 4.68 & 13.4 & 630 \\
Cereal & 30.84 & 5.38 & 3790 \\
Vegetable and fruit & 43.69 & 6.98 & 470 \\
\hline
\end{tabular}

Note: data were from the China Statistical Yearbook, 2015 and the Calorie Control Council.

\section{Results}

\subsection{Human demographics}

In total, 503 completed surveys were received. Participants' basic information is reflected in Table 4 .

\subsection{Animal demographics}

Companion animals' basic information is presented in Table 5 .

\subsection{The ecological paw print and carbon emissions of companion} animals in China

\subsubsection{Individual companion dog}

Our results showed that an average Chinese companion dog could consume $62.43-286.58 \mathrm{~kg}$ leftover food or $47.72-242.91 \mathrm{~kg}$ commercial dry food in a year. We found significant correlations between food consumption per unit body weight and companion dogs' age $(r=0.166, p=0.001)$, size $(r=0.296, p<0.001)$, sterilization station $(r=0.160, p=0.002)$, and their activity time $(r=0.131, p=0.011)$, although the relationships were not strong. In China, the natural gas consumptions for per kg dry pet food production and per $\mathrm{kg}$ human food cooking are $0.12,249 \mathrm{~kg}$ and $0.03762 \mathrm{~kg}$, respectively, while the electric consumption for per $\mathrm{kg}$ food transportation is $0.04 \mathrm{kWh}$ (calculated based on the data from the China Statistical Yearbook). According to this information, we calculated that the EPP of commercial dry food production and human food cooking was $0.039 \mathrm{ha} /$ ton and $0.012 \mathrm{ha} /$ ton, respectively, and the EPP of food transportation was $0.021 \mathrm{ha} /$ ton. Based on companion dogs' size and food consumption (including fresh food ingredients, food production and transportation), we calculated their dietary EPP and carbon emissions regarding different food types. Our results showed that a large dog's dietary EPP and carbon emissions were much higher than that of a small dog. The dietary EPP and carbon emissions of an average-sized dog relying on commercial dry food were ca. eight and three times higher than those of the dog relying on human leftover food (Table 6). Generally, the average lifespan of a dog is around 10-12 years, but there are cases where dogs have reached the age of 17-22 years, depending on the variety and size (Lazăr et al., 2016; Shaw, 1892). In the present study, we estimated the lifespan of an average dog is 12 years and their annual food consumption would not change over time. According to their food consumption during their whole life, we found that the dietary EPP of an average-sized dog relying on leftover food was $1.37-6.31$ ha, which was responsible for the release of up to $0.164-0.769$ tons of carbon dioxide. However, assuming they eat commercial dry food during their whole life, then the dietary EPP of an average-sized dog would increase to $9.92-50.49$ ha, which was responsible for up to $0.449-2.285$ tons carbon emissions (Table 6).

\subsubsection{Individual companion cat}

An average cat could consume $20.11-33.63 \mathrm{~kg}_{\text {year }}{ }^{-1}$ of commercial dry food, and the dietary EPP and carbon emissions of one cat were $0.36-0.63$ ha year $^{-1}$, and $0.024-0.040$ tons. year ${ }^{-1}$, respectively (Table 6). In general, the average lifespan of a cat is around 14 years (Lazăr et al., 2016; Shaw, 1892). Therefore, the whole-life dietary EPP of a cat relying on commercial dry food was 5.06-8.85 ha, which was responsible for the release of up to $0.334-0.558$ tons of carbon dioxide (Table 6). Additionally, we also analyzed the correlation between food consumption and cats' gender, age, the sterilization stations, as well as their activity time. However, we did not find any significant correlations (data not presented in Table). 
Table 2

The ingredients, metabolizable energy, and price of commercial companion animal food.

\begin{tabular}{|c|c|c|c|c|c|}
\hline & Small dog & Middle dog & Large dog & Dog (average) & Cat (average) \\
\hline Protein (\%) & 26.60 & 25.19 & 23.91 & 25.21 & 29.15 \\
\hline Fat $(\%)$ & 14.14 & 14.66 & 12.73 & 13.80 & 13.17 \\
\hline Ash (\%) & 9.20 & 8.83 & 9.59 & 9.23 & 8.39 \\
\hline Fiber (\%) & 3.80 & 3.39 & 3.92 & 3.72 & 4.66 \\
\hline Moisture (\%) & 10.43 & 10.51 & 10.44 & 10.44 & 8.75 \\
\hline Carbohydrate (\%) & 35.83 & 34.42 & 39.41 & 37.60 & 35.88 \\
\hline$M E_{c}(\mathrm{kcal} / \mathrm{kg})$ & 3386.95 & 3332.45 & 3298.25 & 3371.35 & 3395.50 \\
\hline Price $(\mathrm{CNY} / \mathrm{kg})$ & 39.82 & 32.48 & 30.18 & 34.08 & 51.57 \\
\hline
\end{tabular}

Note: data were calculated according to the information from seven most popular pet food brands.

Table 3

The annual average productivity and equivalence factor of different land types.

\begin{tabular}{llll}
\hline Items & $\begin{array}{l}\text { Annual average } \\
\text { productivity }\end{array}$ & $\begin{array}{l}\text { Equivalence } \\
\text { factor }\end{array}$ & Land type \\
\hline Food & & & \\
Beef and mutton & 33 & 0.5 & Grazing land \\
pork & 74 & 0.5 & Grazing land \\
Poultry & 33 & 0.5 & Grazing land \\
Fish & 29 & 0.2 & Fishing grounds \\
Oil & 1856 & 2.8 & Arable land \\
Egg & 400 & 0.5 & Grazing land \\
Milk & 502 & 0.5 & Grazing land \\
Cereal & 2744 & 2.8 & Arable land \\
Vegetable and fruit & 18,000 & 2.8 & Arable land \\
Energy & 5.2 & 1.1 & Energy land \\
\hline
\end{tabular}

*Note: Carbon emission factor is 0.409 , the $\mathrm{C}-\mathrm{CO}_{2}$ transformation factor is 3.67 (Liu et al., 2017).

Table 4

The basic information of participants.

\begin{tabular}{ll}
\hline & $\mathrm{N}(\%)$ \\
\hline Gender & \\
Male & $240(47.7)$ \\
Female & $263(52.3)$ \\
Age & \\
18-29 years & $118(23.5)$ \\
30-39 years & $164(32.6)$ \\
40-49 years & $116(23.1)$ \\
$50-59$ years & $80(15.9)$ \\
60 years and older & $25(5.0)$ \\
Highest Level of Education & \\
Less than grade 12 & $6(1.2)$ \\
High school & $32(6.4)$ \\
College or technical school & $96(19.1)$ \\
University and above & $369(73.4)$ \\
Place of Residence & \\
Urban areas & $483(96.0)$ \\
Rural areas & $20(4.0)$ \\
Career Types & \\
Liberal profession & $50(9.9)$ \\
Employed & $386(76.7)$ \\
Retired & $23(4.6)$ \\
Student & $28(5.6)$ \\
Social welfare & $3(0.6)$ \\
Other & $3(0.6)$ \\
Organization Participation & \\
Conservation of the natural environment & $259(51.5)$ \\
Improving human rights or health & $351(69.8)$ \\
\hline & $252(50.1)$ \\
\hline N &
\end{tabular}

Note: $\mathrm{N}$ means the number of responses; \% means the percentage of responses in each item. (1) This research suffered from a somewhat unbalanced distribution of participants. Only $4 \%$ of the surveys originated from rural areas because of the less internet access in rural areas, people's reluctance to respond and their relatively lower level of education.

\subsubsection{Total companion dogs and cats}

The China industry information network estimated that there were 27.4 million companion dogs and 58.1 million companion cats in China in 2015. Our results showed that the dietary EPP of an average-sized dog relying on leftover food was $0.11-0.53$ ha year ${ }^{-1}$. Multiplied by the estimated number of companion dogs in China, this leads to an estimate of 3.1-14.5 million ha. year ${ }^{-1}$ of the dietary EPP, which was responsible for up to 0.4 to 1.7 million tons of carbon emissions. The dietary EPP of an average-sized dog relying on commercial dry food was $0.82-4.20$ ha year $^{-1}$. This leads to an estimate of 22.6-115.2 million ha. year ${ }^{-1}$ of the dietary EPP for the total dogs, which was responsible for up to 1.0 to 5.2 million tons of carbon emissions (Table 7). With regard to cats, the dietary EPP of all companion cats relying on commercial dry food was 21.0-36.7 million ha. year ${ }^{-1}$, which was responsible for up to 1.4 to 2.3 million tons of carbon emissions (Table 7).

According to the data from the China Statistical Yearbook, 2015, the per capita food consumption by human was $354 \mathrm{~kg} \mathrm{year}^{-1}$. As calculated, the per capita dietary EF in China was 0.62 ha year $^{-1}$, which yielded an estimate of 0.070 tons of carbon emissions (Table 8). Assuming all companion dogs and cats eat commercial dry food, their total dietary EPP was equal to the entire dietary EF of $5.1 \%-17.8 \%$ (70.3-245.0 million) of Chinese people, while the total carbon emissions of food consumption by these companion dogs and cats were equal to the entire dietary carbon emissions of $2.5 \%$ 7.8\% (34.3-107.1 million) of Chinese people.

\subsection{The energy requirement and energy consumption of companion animals in China}

The results of the analysis regarding the energy requirement are included in Fig. 2. According to our data, the body weight of $10-29 \mathrm{~kg}$ was used to represent average dog weight. We found that an average-sized dog's RER and MER were 143,678 to

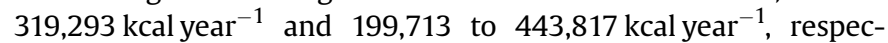
tively. The energy they finally consumed regarding leftover food and commercial dry food varied from 125,999 to $578,387 \mathrm{kcal} \mathrm{year}^{-1}$ and 160,881 to $818,935 \mathrm{kcal} \mathrm{year}^{-1}$, respectively. The calorie intake for many dogs (in particular middle-sized and large dogs) relying on commercial dry food was much higher than their actual needs (Fig. 2). For cats, the body weight of $2-6 \mathrm{~kg}$ was used to represent average cat weight, and an average cat's RER and MER were 42,970 to 97,950 $\mathrm{kcal}^{-1} \mathrm{ear}^{-1}$ and 54,572 to 124,396 kcal year $^{-1}$, respectively. The energy they finally got from commercial dry food ranged from 68,284 to $114,191 \mathrm{kcal}_{\text {year }}{ }^{-1}$. The calorie intake from commercial dry food was sufficient to offset their actual energy requirement (Fig. 2).

In order to reduce overfeeding and food waste, Fig. 3 showed an overview of the feeding directions concerning different food types. The recommended food consumption for each diet was determined on the basis of MER. 
Table 5

The basic information of animals.

\begin{tabular}{|c|c|c|}
\hline & Dog: $N(\%)$ & Cat: $\mathrm{N}(\%)$ \\
\hline Animal species & $373(74.2)$ & $130(25.8)$ \\
\hline \multicolumn{3}{|l|}{ Gender } \\
\hline Male & $231(91.9)$ & $62(47.7)$ \\
\hline Female & $142(38.1)$ & $68(52.3)$ \\
\hline \multicolumn{3}{|l|}{ Age } \\
\hline$<5$ years & $227(60.9)$ & $77(59.2)$ \\
\hline $5-10$ ears & $128(34.3)$ & $44(33.8)$ \\
\hline$>10$ years & $18(4.8)$ & $9(6.9)$ \\
\hline \multicolumn{3}{|l|}{ Size } \\
\hline Small $(1.5-10 \mathrm{~kg})^{(1)}$ & $113(30.3)$ & - \\
\hline Middle (10-25 kg) & $190(50.9)$ & - \\
\hline Large $(25-70 \mathrm{~kg})^{2}$ & $70(13.9)$ & - \\
\hline \multicolumn{3}{|l|}{ Food consumption } \\
\hline Dog: $<10$ g.BW ${ }^{-1}$.day ${ }^{-1(3)} ;$ Cat: $<50$ g.day ${ }^{-14}$ & $69(18.5)$ & $19(14.6)$ \\
\hline Dog:10-25 g.BW ${ }^{-1}$ day $^{-1}$; Cat: $50-100$ g.day $^{-1}$ & $233(62.5)$ & $84(64.6)$ \\
\hline Dog: $>25$ g.BW ${ }^{-1}$ day $^{-1}$; Cat: $>100$ g.day $^{-1}$ & $48(12.9)$ & $18(13.8)$ \\
\hline No idea & $23(6.2)$ & $9(6.9)$ \\
\hline \multicolumn{3}{|l|}{ Health condition } \\
\hline Good & $299(80.2)$ & $100(76.9)$ \\
\hline Fair & $70(18.8)$ & $30(23.1)$ \\
\hline Bad & $4(1.1)$ & $0(0)$ \\
\hline \multicolumn{3}{|l|}{ Sterilization conditions } \\
\hline Neutered & $91(24.4)$ & $46(35.4)$ \\
\hline Sexually intact & $282(75.6)$ & $84(64.6)$ \\
\hline \multicolumn{3}{|l|}{ Activity } \\
\hline Dog: <1 h; Cat: Never & $157(42.1)$ & $45(34.6)$ \\
\hline Dog: $1-2$ h; Cat: Sometimes & $201(53.9)$ & $69(53.1)$ \\
\hline Dog: $>2$ h; Cat: Whole day & $15(4.0)$ & $16(12.3)$ \\
\hline Significantly overweight ${ }^{(5)}$ & $11(2.9)$ & - \\
\hline
\end{tabular}

Note: $\mathrm{N}$ means the number of responses; \% means the percentage of responses in each item. (1) The Chihuahua is the smallest dog breed in the world (also in our study) (Knowler et al., 2017) and The Fédération Cynologique Internationale (FCI) standard states that an adult Chihuahua in general not weight less than $1.5 \mathrm{~kg}$. Therefore, we set the minimum value for dog weight as $1.5 \mathrm{~kg}$. (2) The Tibetan Mastiff is the largest dog breed in China (as well as in this study), and an adult companion Tibetan Mastiff generally not weight more than $70 \mathrm{~kg}$ (Guo et al., 2015). Therefore, we set the maximum value for dog weight as $70 \mathrm{~kg}$. (3) According to the sample in our study, the minimum resting energy requirement for a companion dog is $24.2 \mathrm{kal} \mathrm{kgBW}^{-1}$.day ${ }^{-1}$, which means Chinese dog owner should give their dog at least $7 \mathrm{~g}$. $\mathrm{kgBW}^{-1}$.day ${ }^{-1}$ of dry food or $12 \mathrm{~g} \cdot \mathrm{kgBW}^{-1}$.day ${ }^{-1}$ of leftovers to keep their dog in good or fair health condition (99.0\% respondents reported their dog's health condition as good or fair). Therefore, in the calculation process, we set the minimum value for dog food consumption as $7 \mathrm{~g} \cdot \mathrm{BW}^{-1}$.day ${ }^{-1}$ and $12 \mathrm{~g} \cdot \mathrm{kgBW}^{-1}$.day ${ }^{-1}$ regarding commercial dry food and leftover food. (4) The body weight of cats (in general 2-6 kg) varies less than that of dogs, so the daily food consumption of cat was asked without considering their body weight. The minimum resting energy requirement for a companion cat is $117.7 \mathrm{kcal}_{\text {.day }}{ }^{-1}$, which means Chinese cat owners should give their cat at least 35 g.day $^{-1}$ of dry food to keep their cat in good or fair health condition (100\% respondents reported their cat's health condition as good or fair). Therefore, in the calculation, we set the minimum value for cat food consumption as 35 g.day $^{-1}$ regarding dry food. (5) Significantly overweight means that the bodyweight of companion dogs exceeds the upper limit of the standard bodyweight of the corresponding breed.

\section{Discussion}

Growing evidence has revealed that owning one or more pets can increase owners' physical activity, decrease their loneliness and improve their sense of physical and psychological well-being (Cutt et al., 2007; Dotson and Hyatt, 2008; Qureshi et al., 2009; Wood et al., 2015).

However, acknowledging their positive bond with humans does not mean neglecting their negative impacts on the environment (Rushforth and Moreau, 2013). The purposes of performing Chinese companion animals' dietary EPP and carbon emissions in the present study were (1) to have a clear view of their food consumption, (2) to investigate their ecological impacts and (3) to raise their owners' awareness of environmental protection and animal wellbeing. The results indicate that companion dogs and cats consumed a significant amount of food energy, resulting in negative environmental impacts such as the huge carbon emissions. This is particularly true given increasing companion animal numbers in China and the high nutritional content of companion animal food (Okin, 2017; Swanson et al., 2013). Measures that would considerably reduce companion animals' environmental impacts should be discussed.

\subsection{Ecological paw print}

Due to the higher percentage of animal products in commercial dry food, the dietary EPP of an individual dog relying on such food was found to be much higher than that of an individual dog relying on leftover food. The dietary EPP of all companion dogs, if assuming they eat human leftover food, was equivalent to $0.4 \%-1.7 \%$ (5.0-23.4 million) of Chinese people's dietary EF. While this number would increase to $2.6 \%-13.5 \%$ (36.5-185.8 million) of Chinese people if assuming all these dogs eat commercial dry food. Therefore, it is clear, at least for countries with a large number of animal populations like China, that the consumption by companion animals should be considered when measuring national environmental performances (Okin, 2017). A large variation of the dietary EPP was also found among different sizes of dogs. Thus, care must be taken when measuring the dietary EPP of different sizes of dogs. Our results also reveal that the dietary EPP of two large dogs relying on commercial dry food was equivalent to 20 Chinese people's dietary EF, or one Chinese people's whole EF (12.46 ha) (Venetoulis and Talberth, 2008). Considering that we only calculated companion dogs' food consumption, we thought the corresponding animal numbers should be reduced if we took their consumption of water, health, and entertainment into account. Inconsistent with a previous study showing that the dietary EPP for a small dog relying on commercial dry food was $0.09-0.18$ ha while for a middle-sized dog (15 kg) was 0.48 ha (Vale and Vale, 2009), our results demonstrated

Table 6

Individual dog and cat's food consumption, dietary ecological paw print (EPP) and carbon emissions regarding leftover food and commercial dry food in China (2015).

\begin{tabular}{|c|c|c|c|c|c|c|}
\hline & \multicolumn{3}{|l|}{ Leftover food } & \multicolumn{3}{|l|}{ Dry food (chicken-based) } \\
\hline & Food consumption (Kg/year) & $\operatorname{EPP}($ ha) & $\mathrm{CO}_{2}$ emissions $(\mathrm{t})$ & Food consumption (Kg/year) & $\mathrm{EPP}$ (ha) & $\mathrm{CO}_{2}$ emissions $(\mathrm{t})$ \\
\hline \multicolumn{7}{|l|}{$\overline{D o g}$} \\
\hline Average-sized dog & $62.43-286.58$ & $0.11-0.53$ & $0.014-0.064$ & $47.72-242.91$ & $0.82-4.20$ & $0.037-0.190$ \\
\hline Small dog & $7.93-91.25$ & $0.01-0.16$ & $0.002-0.021$ & $5.70-68.44$ & $0.10-1.23$ & $0.005-0.063$ \\
\hline Middle-sized dog & $47.12-228.13$ & $0.09-0.42$ & $0.010-0.051$ & $38.67-212.66$ & $0.68-3.75$ & $0.029-0.159$ \\
\hline Large dog & $158.12-638.75$ & $0.30-1.17$ & $0.035-0.143$ & $142.21-615.17$ & $2.32-10.05$ & $0.099-0.427$ \\
\hline One dog (lifetime) & $749.16-3438.96$ & $1.37-6.31$ & $0.164-0.769$ & $572.64-2914.92$ & $9.92-50.49$ & $0.449-2.285$ \\
\hline \multicolumn{7}{|l|}{ Cat } \\
\hline Average-sized cat & - & - & - & $20.11-33.63$ & $0.36-0.63$ & $0.024-0.040$ \\
\hline One cat (lifetime) & - & - & - & $281.54-470.82$ & $5.06-8.85$ & $0.334-0.558$ \\
\hline
\end{tabular}

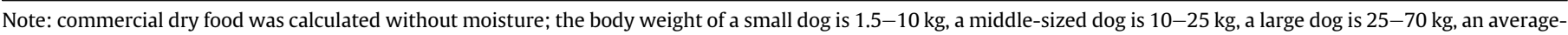
sized dog is $10-29 \mathrm{~kg}$, an average-sized cat is $2-6 \mathrm{~kg}$. 
Table 7

The total food consumption, dietary ecological paw print (EPP) and carbon emissions of Chinese companion dogs and cats in 2015.

\begin{tabular}{|c|c|c|c|c|c|c|}
\hline & \multicolumn{3}{|l|}{ Leftover food } & \multicolumn{3}{|l|}{ dry food (chicken-based) } \\
\hline & Food (million kg/year) & EPP (million ha) & $\begin{array}{l}\mathrm{CO}_{2} \text { emissions } \\
\text { (million tons/year) }\end{array}$ & Food (million kg/year) & EPP (million ha) & $\begin{array}{l}\mathrm{CO}_{2} \text { emissions } \\
\text { (million tons/year) }\end{array}$ \\
\hline Total dog & $1711-7852$ & $3.1-14.5$ & $0.4-1.7$ & $1308-6656$ & $22.6-115.2$ & $1.0-5.2$ \\
\hline Total cat & - & - & - & $1168-1954$ & $21.0-36.7$ & $1.4-2.3$ \\
\hline
\end{tabular}

that the dietary EPP of a small dog relying on commercial dry food was $0.10-1.23 \mathrm{ha}$, while for a middle-sized dog was $0.68-3.75$ ha. One possible explanation might be that our study was conducted

Table 8

The per capita food consumption, ecological footprint and carbon emissions of Chinese people in 2015.

\begin{tabular}{llll}
\hline Human & Food consumption (Kg/year) & $\mathrm{EF}(\mathrm{ha})$ & $\mathrm{CO}_{2}$ emissions $(\mathrm{t})$ \\
\hline Per capita & 354 & 0.62 & 0.070 \\
\hline
\end{tabular}

Note: Data for the food consumption per capita were from Chinese Statistical Yearbook, 2015

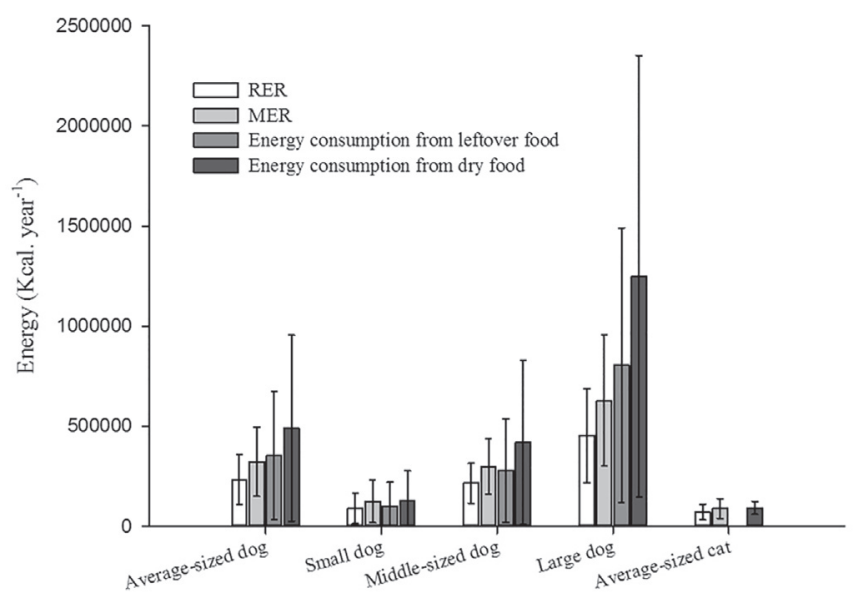

Fig. 2. The resting energy requirement (RER), maintenance energy requirement (MER) and the final energy consumption of individual companion animal in 2015. The error bar means standard deviation (SD).

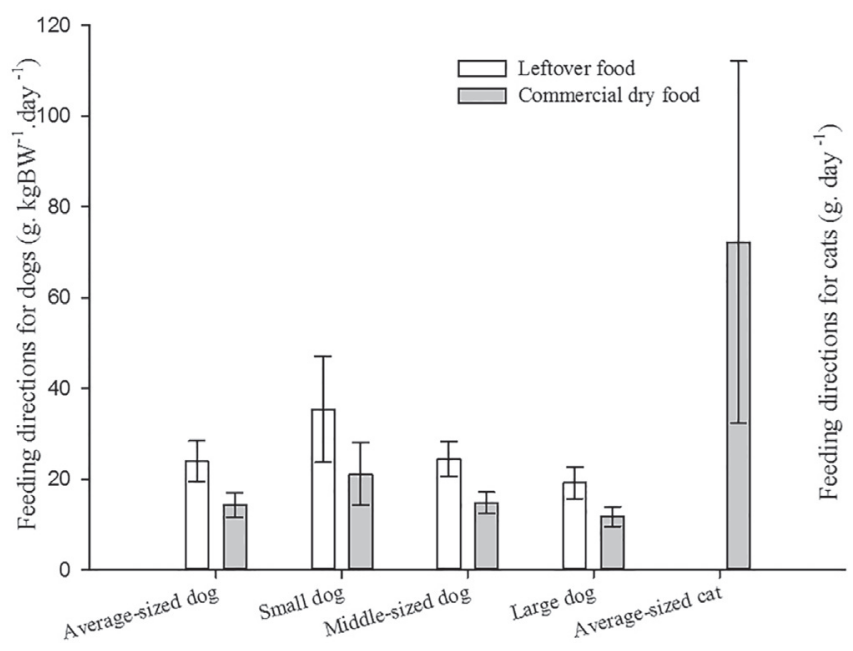

Fig. 3. Feeding directions regarding different food types. The error bar means standard deviation (SD) six years later, and the EPP is a dynamic indicator because the resource consumption of companion animals and the nutritional content of animal food would change over time (Ou and Tan, 2013). Notably, an important caveat for the calculations of the dietary EPP of dogs is that the source of the data and mode of calculation are dramatically different. Therefore, it is not surprising that the results may be systematically different. Considering that a detailed calculation was provided in the present study, with market-wide knowledge of pet food and direct data on food consumption, we think our findings are more representative of dogs' actual food consumption and environmental impacts.

With regard to companion cats, our results indicate that total companion cats' dietary EPP was equal to $2.5 \%-4.3 \%$ (33.9-59.2 million) of Chinese people's dietary $\mathrm{EF}$, or $0.1 \%-0.2 \%(1.7-2.9$ million) of Chinese people's whole EF according to the data from a previous study (Venetoulis and Talberth, 2008). The dietary EPP of an average-sized cat relying on commercial dry food was $0.36-0.63 \mathrm{ha}$, which is basically in accordance with previous findings reporting that the dietary EPP of an average-sized cat was 0.3 ha (Vale and Vale, 2009). An explanation of the similar results is that we used the same approach (according to the fresh chicken that an individual cat consumed, rather than dry chicken) to calculate the dietary EPP of companion cats. Cats have a smaller appetite than dogs, which might be another reason to explain the fact that the cat's dietary EPP would not change too much over time.

The gap between urban and rural areas is one of the most significant characteristics of contemporary China and this gap directly influences household lifestyle including companion animals' feeding regimens (Su and Martens, 2017). For instance, in rural areas, plant-based leftover food and even by-products from agriculture (crop residue and straw) are often used to feed household animals, and the malnutrition problems exist among many companion animals (Li and Davey, 2013). Commercial dry food and leftover food with both plant and animal-based products are more commonly used to feed companion animals in urban areas than in rural animals, and the phenomena of food waste and overfeeding in urban areas are more serious than that in rural areas. These different husbandry activities between rural and urban areas will lead to different dietary EPP of companion animals. However, in this study, only $4 \%$ of the surveys originated from rural areas probably due to limited internet access in such places, people's reluctance to respond and their relatively lower level of education (Su and Martens, 2017). This would to some extent bias our results. Yet, considering that dogs and cats in rural areas are generally viewed as working animals and have roles in civilian security and pest control (Cao, 2015; Headey et al., 2008), we feel that the influences of unbalanced samples are minimal and can be reasonably neglected in the present study.

\subsection{Carbon emissions}

Companion animals' food consumption is often neglected by their owners and researchers, although it actually contributes to a significant proportion of carbon emissions. As calculated, the 
carbon emissions from commercial dry food consumption by all companion dogs and cats in China were equal to $2.5 \%-7.8 \%$ (34.3-107.1 million) of Chinese people's dietary carbon emissions. The increasing pet ownership in contemporary China may also serve to increase the potential carbon emissions of pet dogs and cats (Okin, 2017).

Meat plays a large role in determining the environmental impacts of an individual animal's diet. Our results demonstrate that due to the higher meat content, carbon emissions derived from animals' commercial dry food were higher than that from leftover food. It could be argued that dogs and cats eat meat that humans cannot consume and which is simply a byproduct of production for human use, and therefore should not be counted when calculating their carbon emissions (Okin, 2017). However, many ingredients (e.g., chicken liver) in pet food can certainly be edible after processing (Okin, 2017). The trend toward premium pet food with more animal products that Chinese people would recognize as edible indicates that companion animals are eating animal products that could also be eaten by humans (Okin, 2017). This reminds us that a direct competition of some ingredients exists between animal food and human food systems (Swanson et al., 2013), and therefore companion animals' food-derived environmental impacts cannot be neglected.

Inasmuch as increasing animal production is a threat to Chinese and even global environment, the non-negligible contribution of dogs and cats compounds the problem and exacerbates the threat to sustainability posted by human consumption (Okin, 2017; Tilman et al., 2011; Tilman and Clark, 2014). The results from the present study suggest that additional research is needed to evaluate the animal content and human-edibility of ingredients in dog and cat food after processing. The calculations presented here indicate that companion animals comprise a significant proportion of total energy and animal product consumption in China, with a considerably great impact on carbon emissions (Tilman and Clark, 2014). Additionally, since many dogs and cats in rural areas are not registered and licensed, we suppose the environmental impacts by companion animals would increase dramatically if including all companion animals in rural areas, although their owners prefer to feed them more plant-based food than animal-based food.

\subsection{Energy requirement}

In view of that the RER does not consider animal gender, age, size or activities (Fleeman and Owens, 2007), we provided both the RER and the MER in the present study. Interestingly, there might be some floor effects that made small and middle-sized dogs' minimum energy consumption lower than their minimum MER, but our results demonstrate that some companion animals, particularly middle-sized and large dogs, consumed more food than their actual needs to keep normal activity. This may directly lead to animal obesity, which is not only associated with numerous diseases, but also with resource consumption and environmental degradation. For overweight or obese companion animals, the extra weight would require more calories and the environmental impacts due to overfeeding would be more severe. This reminds us that the environmental degradation resulted from overweight and obesity should be quantified in the future studies, especially for those will be conducted in countries with many obese companion animals. It also indicates that greater calorie restriction is necessary to keep companion animals' standard body weight and simultaneously reduce their energy consumption and environmental impacts.

Fortunately, companion animal obesity in China is not as common as that in developed countries, but a trend is seen towards higher energy consumptions by companion animals. Pet food is a major source of calories for companion animals. Therefore, efforts to reduce overfeeding and food waste should be considered in order to reduce their environmental impacts. Many companion animal owners and even veterinarians rely on the recommendations in the pet food's label (Linder and Freeman, 2010). However, based on consumer demand, many commercial pet goods are formulated to provide excessive nutrients, resulting in overfeeding, energy waste and animal obesity. To ensure both human society and pet ownership can be sustained in the future, the pet food industry should provide accurate information about the nutrition and portion sizes of pet food, and guarantee that the pet food should be economically affordable and culturally acceptable, and should effectively satisfy the needs for the good health of animals as pets. In addition, pet food companies could assist in improving pet health by developing foods with appropriate caloric density on a volume basis, and making more accurate and specific feeding directions regarding animal size, age, breed and activity (Linder and Freeman, 2010; Swanson et al., 2013).

It should be mentioned that diet selection and control of calories from animal diets are important, but they are not the only two components for a healthy weight control intervention (Linder and Freeman, 2010). Companion animals vary greatly in their energy requirements, and it is necessary to adjust feeding recommendations for each animal (Linder and Freeman, 2010). This requires companion animal owners to pay more diligent attention to their animals' activity and health condition. The information this study provides should be of use to Chinese pet owners, veterinarians and pet food manufacturers in understanding the energy and nutritional requirement of companion dogs and cats.

\subsection{Indicator analysis: use of the ecological paw print in animal welfare and sustainable development}

Scientific evaluation of companion animals' dietary EPP, energy requirement, and environmental impacts can provide valuable insights to pet owners and policymakers so that the awareness of animal welfare can be improved and the sustainable development patterns can be recognized (Geng et al., 2014). According to our study, close attention should be paid to the feeding directions of different food types, which are related to both environmental degradation and animal health. By comparing companion animals' energy requirement and consumption, owners can be reminded to consider their animals' health conditions, which is good for improving the awareness of animal welfare (Su and Martens, 2017). Since animal-based products, compared to plant-based products, have considerably greater impacts on the environment, some companion animal owners are suggested to feed their animals with more plant-based food, or human leftover food which includes less animal-based products than commercial dry food. However, due to the nutrient deficiencies and food safety issues, the plant-based food and human leftover food may lead to health risks to companion animals, such as the long-term complications varying from the poor skin to chronic diarrhea (Laflamme et al., 2008; Weeth, 2013). Therefore, when caring for companion animals' food consumption and the environmental impacts, owners and policymakers should focus on animal welfare, based on which the approaches of low dietary EPP and carbon emissions should be emphasized in feeding regimens and mitigation policies (Xu et al., 2016).

The number of dog- and cat-owning households is increasing in China, and at the same time, there is an increasing trend in the high nutritional content of pet food. As a possible consequence, obesity will become a major problem among companion animals in China.

Therefore, the pet food industry should start to confront the issue of the sustainability of feeding pets through advances in product design and manufacturing in order to avoid overfeeding 
and food waste (Okin, 2017). Additionally, future energy policies should be oriented toward encouraging recycling and finding alternative sources of protein (Okin, 2017; Swanson et al., 2013). We suppose such measures would reduce companion animals' environmental impacts. However, in order to drastically reduce their dietary EPP and environmental impacts, other measures such as changing the food system, replacing large animals with small ones that can provide the same physical and psychological benefits to humans and reducing companion animal numbers should be considered.

\subsection{Limitation of this study}

This research is the first to examine the dietary EPP, carbon emissions and energy consumptions of companion dogs and cats in China. Hence, it inevitably involves some limitations. For example, there is quite a bit of uncertainty regarding the exact amount of food (particularly leftover food) eaten by companion animals. Many Chinese companion animal owners give their animals leftover food mixed with dry food or prepare pure meat food (or commercial canned food) when their animals are sick or when they are bored with the normal food (i.e., leftover food and dry food). It is not possible for respondents to provide the accurate percentages of different food types. This may result in the uncertainty dietary EPP of an individual companion animal. However, in the present study, we analyzed companion dog and cat's dietary EPP regarding each food type, which has primarily addressed this problem. Additionally, asking respondents to provide the exact body weight of their companion animals is very difficult if we want to collect more samples. Therefore, we provided three possible body weight ranges to respondents, and consequently, the results of the dietary EPP, carbon emissions and energy consumptions were also displayed as ranges. In order to cover all the possible answers and simultaneously make the calculation possible, we provided the minimum body weight and food consumption per unit body weight, as well as the maximum body weight of companion animals. This may lead to the larger ranges of the EPP, carbon emissions and energy consumptions. Nevertheless, this also reminds us that research with specific values of body weight and resource consumption should be conducted in the future. Due to the manner of information collection, this research suffered from a somewhat unbalanced distribution of participants. For instance, the number of urban respondents was much higher than that of rural respondents. As we mentioned above, this might make our results of the dietary environmental impacts of companion animals slightly more severe than the real scenario because most of the companion animal owners in rural areas prefer to feed their animals with more or even all plant-based leftover food. However, given that dogs and cats in rural areas are not generally viewed as companion animals (Headey et al., 2008), this limitation can be reasonably neglected in the present study.

\section{Conclusion}

Animal companionship can benefit physiological, psychological as well as social aspects of human life. However, their contribution to the environmental degradation is crucial to sustainability and therefore should not be neglected. Calculating the dietary EPP and carbon emissions of companion dogs and cats in China is an important way to contextualize their different dietary choices in environmental protection. This research developed an accurate and accessible method for companion animals' dietary EPP calculation and quantified the significant environmental impacts by investigating their dietary carbon emissions. Our results showed that the dietary EPP and carbon emissions of an average-sized dog relying on commercial dry food were much higher than those of the dog relying on human leftover food because animals' commercial dry food, compared to human leftover food, includes more animal products, requires more land and has greater environmental consequences in terms of carbon emissions in China. The dietary EPP of all Chinese companion dogs and cats, assuming they eat commercial dry food, was equivalent to the dietary EF of $5.1 \%-17.8 \%$ (70.3-245.0 million) of Chinese people in 2015. The annual food consumption of all these dogs and cats was responsible for up to 2.4-7.5 million tons carbon emissions, which was equivalent to the entire carbon emissions of 2.5\%-7.8\% (34.3-107.1 million) of Chinese people in terms of food consumption in 2015. Additionally, our results demonstrated that many companion animals (especially large dogs) consumed more energy than their actual needs to keep normal activity.

As pet ownership increases in China and trends continue in pet food towards higher percentages of animal products, pet ownership will definitely aggravate environmental degradation and exacerbate the threat to the sustainability. Therefore, finding ways to reduce the entire resource consumptions by companion animals not only in China but also in other countries with a large animal population is significant to the well-being of future generations. It is clear that a transition to companion animal owners that avoid overfeeding and food (especially animal products) waste would reduce the overall food consumption and the environmental damage in China. Additionally, our findings demonstrate that animal (dog) size is significantly correlated with food and energy consumption, the smaller the animals, the lower the dietary EPP and carbon emissions. Therefore, replacing large dogs with small dogs or cats that offer similar health and emotional benefits would considerably reduce their environmental impacts (Okin, 2017).

This study investigated the relationship between companion animals' food consumption and their environmental impacts. It aimed to improve owners and even all Chinese people's awareness of sustainability and ultimately promote the whole country's sustainable development. Quantifying the precise relationship between companion animals' food consumption and their environmental impacts needs owners to provide the detail information of their animals' food consumption, body weight, and activity level. Research with specific values of these variables, therefore, should be conducted in the near future. Besides food consumption, companion animals also need water, living spaces, entertainment, health care and other resources and services, which would dramatically exacerbate their environmental impacts. Hence, a broader quantification of companion animals' all aspects of resource consumptions is needed to be designed and tested. Another interesting avenue for future research is using the framework of the dietary EPP to assess the relationship between the environmental impacts and the food consumption by other animal types, such as farm animals, wild animals, zoo animals, working animals and laboratory animals. Additionally, we should admit that there is no single evaluation approach can present all dimensions of sustainability (Geng et al., 2014). It may be necessary to integrate EPP analysis with other evaluation frameworks so that more scientific sustainable approaches can be addressed for minimizing resource consumption and simultaneously maximizing the sustainability of a country as a whole. Despite the difficulties inherent in studying animals particularly companion animals' environmental impacts, we believe such research is necessary if we wish to make sense of the manner in which other species are related to the environmental world.

\section{Data accessibility}

Data is available from figshare repository: https://figshare.com/ s/98cd0ee2a533adc30fe1. 


\section{Declaration of interest}

Authors have no conflicts of interest with this publication.

\section{Acknowledgement}

We thank the reviewers for their comments; these improved the paper. We acknowledge the effort of Flycatcher for their help with the data collection. We thank all the dog and cat owners for their participation in the survey.

\section{References}

Bin, S., Dowlatabadi, H., 2005. Consumer lifestyle approach to US energy use and the related CO 2 emissions. Energy Pol. 33 (2), 197-208.

Canning, P., 2011. Energy Use in the US Food System. Diane Publishing.

Cao, D., 2015. Animals in China: Law and Society. Springer.

Carrión, P.A., Thompson, L.J., 2014. In: Motarjemi, Y., Lelieveld, H. (Eds.), Pet Food. Food Safety Management: a Practical Guide for the Food Industry, pp. 379-395.

Cutt, H., Giles-Corti, B., Knuiman, M., Burke, V., 2007. Dog ownership, health and physical activity: a critical review of the literature. Health Place 13 (1), 261-272.

Dotson, M.J., Hyatt, E.M., 2008. Understanding dog-human companionship. J. Bus. Res. 61 (5), 457-466.

Du, B., Zhang, K., Song, G., Wen, Z., 2006. Methodology for an urban ecological footprint to evaluate sustainable development in China. Int. J. Sustain. Dev. World Ecol. 13 (4), 245-254.

Fiala, N., 2008. Measuring sustainability: why the ecological footprint is bad economics and bad environmental science. Ecol. Econ. 67 (4), 519-525.

Fleeman, L.M., Owens, E., 2007. Applied animal nutrition. Animal Physiother: Assess. Treat. Rehabil. Animals 14-31.

Flynn, M., Hardie, E., Armstrong, P., 1996. Effect of ovariohysterectomy on maintenance energy requirement in cats. J. Am. Vet. Med. Assoc. 209 (9), 1572-1581.

Friedmann, E., Thomas, S.A., 1995. Pet ownership, social support, and one-year survival after acute myocardial infarction in the Cardiac Arrhythmia Suppression Trial (CAST). Am. J. Cardiol. 76 (17), 1213-1217.

Fu, W., Turner, J.C., Zhao, J., Du, G., 2015. Ecological footprint (EF): an expanded role in calculating resource productivity (RP) using China and the G20 member countries as examples. Ecol. Indicat. 48, 464-471.

Gao, J., Tian, M., 2016. Analysis of over-consumption of natural resources and the ecological trade deficit in China based on ecological footprints. Ecol. Indicat. 61, 899-904.

Geng, Y., Zhang, L., Chen, X., Xue, B., Fujita, T., Dong, H., 2014. Urban ecological footprint analysis: a comparative study between Shenyang in China and Kawasaki in Japan. J. Clean. Prod. 75, 130-142.

Guo, W., Xu, S., Zhang, J., Xue, X., Yang, G., Lu, Y., Guo, Z., Yang, Y., Xu, C., 2015. Research on different types of Tibetan mastiffs in the qinghai-tibet plateau. Heilongjiang J. Animal Breed. 23 (4), 5-7 (in Chinese).

Headey, B., Na, F., Zheng, R., 2008. Pet dogs benefit owners' health: a 'natural experiment'in China. Soc. Indicat. Res. 87 (3), 481-493.

Jones, A., Ackerman, N., 2016. Canine and Feline Nutrition. Aspinall's Complete Textbook of Veterinary Nursing. Elsevier, p. 145.

Kitzes, J., Wackernagel, M., Loh, J., Peller, A., Goldfinger, S., Cheng, D., Tea, K., 2008. Shrink and share: humanity's present and future Ecological Footprint. Philos. Trans. R. Soc. Lond. B Biol. Sci. 363 (1491), 467-475.

Knowler, S.P., Kiviranta, A.-M., McFadyen, A.K., Jokinen, T.S., La Ragione, R.M. Rusbridge, C., 2017. Craniometric analysis of the Hindbrain and Craniocervical Junction of Chihuahua, Affenpinscher and Cavalier King Charles Spaniel dogs with and without Syringomyelia secondary to Chiari-like Malformation. PLoS One 12 (1), e0169898.

Laflamme, D.P., Abood, S.K., Fascetti, A.J., Fleeman, L.M., Freeman, L.M., Michel, K.E., Bauer, C., Kemp, B.L., Doren, J.R.V., Willoughby, K.N., 2008. Pet feeding practices of dog and cat owners in the United States and Australia. J. Am. Vet. Med. Assoc. 232 (5), 687-694.

Lambrechts, W., Van Liedekerke, L., 2014. Using ecological footprint analysis in higher education: campus operations, policy development and educational purposes. Ecol. Indicat. 45, 402-406.

Lazăr, C., Mărgărit, M., Bălășescu, A., 2016. Dogs, jaws, and other stories: two symbolic objects made of dog mandibles from southeastern Europe. J. Field Archaeol. 41 (1), 101-117.

Li, P.J., Davey, G., 2013. Culture, reform politics, and future directions: a review of China's animal protection challenge. Soc. Anim. 21 (1), 34-53.

Linder, D.E., Freeman, L.M., 2010. Evaluation of calorie density and feeding directions for commercially available diets designed for weight loss in dogs and cats. J. Am. Vet. Med. Assoc. 236 (1), 74-77.

Liu, H., Wang, X., Yang, J., Zhou, X., Liu, Y., 2017. The ecological footprint evaluation of low carbon campuses based on life cycle assessment: a case study of Tianjin, China. J. Clean. Prod. 144, 266-278.
Meldrum, H., Szymanski, D., Oches, E.A., Davis, P.T., 2017. Speaking Out or Staying Quiet on Climate Change: Broadcast Meteorologists Influenced by the Need to Be Pithy, Popular and Politically Cautious, Climate Change Adaptation in North America. Springer, pp. 261-277.

MIIT, 2015. In: Technology, M.o.I.a.I (Ed.), Yearbook of China Information Industry. City Press of China, Beijing.

Mukherjee, K., 2008. Energy use efficiency in US manufacturing: a nonparametric analysis. Energy Econ. 30 (1), 76-96.

Okin, G.S., 2017. Environmental impacts of food consumption by dogs and cats. PLoS One 12 (8), e0181301.

Ou, G.L., Tan, S.K., 2013. Study on Sustainable Use of Land Based on Ecological Footprint Model: a Case of Shenzhen, Applied Mechanics and Materials. Trans Tech Publ, pp. 2551-2556.

Qureshi, A.I., Memon, M.Z., Vazquez, G., Suri, M.F.K., 2009. Cat ownership and the risk of fatal cardiovascular diseases. Results from the second national health and nutrition examination study mortality follow-up study. J. Vasc. Intervent. Neurol. 2 (1), 132-135.

Ravilious, K., 2009. How green is your pet? N. Sci. 204 (2731), 46-47.

Reijnders, L., Soret, S., 2003. Quantification of the environmental impact of different dietary protein choices. Am. J. Clin. Nutr. 78 (3), 664S-668S.

Rushforth, R., Moreau, M., 2013. Finding Your Dog's Ecological'Pawprint': a Hybrid EIO-lca of Dog Food Manufacturing. SSEBE-CESEM-2013-CPR-005, Course Project Report Series.

Schwartz, L., 2014. The Surprisingly Large Carbon Paw Print of Your Beloved Pet. http://www.salon.com/2014/11/20/the_surprisingly_large_carbon_paw_print_ of_your_beloved_pet_partner/. (Accessed 12 February 2017).

Shaw, F.W. 1892. Age of the domestic animals. Ann. Surg. 16 (4), 397-399.

Shi, X., Ma, Y., Wang, Q., Gao, K., Liu, X., 2015. Geo-informatics in Resource Management and Sustainable Ecosystem.

Streeter, R.M., Wakshlag, J.J., 2015. Nutritional support in hepatic failure in dogs and cats. Nutr. Manag. Hosp. Small Animals 199-209.

Su, B., Koda, N., Martens, P., 2018. How Japanese companion dog and cat owners' degree of attachment relates to the attribution of emotions to their animals. PLoS One 13 (1), e0190781.

Su, B., Martens, P., 2017. Public attitudes toward animals and the influential factors in contemporary China. Anim. Welf. 26 (2), 239-247.

Swanson, K.S., Carter, R.A., Yount, T.P., Aretz, J., Buff, P.R., 2013. Nutritional sustainability of pet foods. Adv. Nutr.: Int. Rev. J. 4 (2), 141-150.

Szigeti, C., Tóth, G., Borzán, A., Farkas, S., 2013. GDP alternatives and their correlations. J. Environ. Sustain. 3 (3), 35-46.

Thatcher, C., Hand, M., Remillard, R.L., 2010. Small animal clinical nutrition: an iterative process. Small Animal Clin. Nutr. 5, 3-21. Hand MS, Thatcher CD, Remillard RL, et al.

Tilman, D., Balzer, C., Hill, J., Befort, B.L., 2011. Global food demand and the sustainable intensification of agriculture. Proc. Natl. Acad. Sci. Unit. States Am. 108 (50), 20260-20264.

Tilman, D., Clark, M., 2014. Global diets link environmental sustainability and human health. Nature 515 (7528), 518-522.

Toth, G., Szigeti, C., 2016. The historical ecological footprint: from over-population to over-consumption. Ecol. Indicat. 60, 283-291.

Vale, Vale, 2009. Time to Eat the Dog? the Real Guide to Sustainable Living. Thames \& Hudson.

Venetoulis, J., Talberth, J., 2008. Refining the ecological footprint. Environ. Dev. Sustain. 10 (4), 441-469.

Wackernagel, M., Onisto, L., Bello, P., Linares, A.C., Falfán, I.S.L., Garcia, J.M. Guerrero, A.I.S., Guerrero, M.G.S., 1999. National natural capital accounting with the ecological footprint concept. Ecol. Econ. 29 (3), 375-390.

Wackernagel, M., Rees, W., 1998. Our Ecological Footprint: Reducing Human Impact on the Earth. New Society Publishers.

Wakeland, W., Cholette, S., Venkat, K., 2012. Food Transportation Issues and Reducing Carbon Footprint, Green Technologies in Food Production and Processing. Springer, pp. 211-236.

Wang, K., Feng, G., Ye, T., Wang, X., Liu, P., 2016. The variation characteristics of Asian surface temperature and precipitation in the early 21 st century. Discrete Dynam. Nat. Soc. 2016.

Weeth, L.P., 2013. Focus on nutrition: home-prepared diets for dogs and cats. Compendium 35 (3), E1-E3.

Wei, Y.-M., Liu, L.-C., Fan, Y., Wu, G., 2007. The impact of lifestyle on energy use and CO 2 emission: an empirical analysis of China's residents. Energy Pol. 35 (1), 247-257.

Wood, L., Martin, K., Christian, H., Nathan, A., Lauritsen, C., Houghton, S., Kawachi, I., McCune, S., 2015. The pet factor-companion animals as a conduit for getting to know people, friendship formation and social support. PLoS One 10 (4), e0122085.

Wu, L., He, Y., Jiang, B., Sun, D., Wang, J., Liu, M., Yang, S., Wang, Y., 2015. Trends in prevalence, awareness, treatment and control of hypertension during 2001 2010 in an urban elderly population of China. PLoS One 10 (8), e0132814.

Xu, X., Han, L., Lv, X., 2016. Household carbon inequality in urban China, its sources and determinants. Ecol. Econ. 128, 77-86. 